\title{
A Novel Active Damping Control of a Three-phase PWM Inverter with LC Filter
}

\author{
Kwang-Seob Kim* and Dong-Seok Hyun ${ }^{\dagger}$
}

\begin{abstract}
A novel control method of a three-phase PWM inverter with LC filter is proposed. The transfer function of LC filter is the same as that of 2nd order low pass filter(2nd LPF) which has a zero damping ratio. A simple method of implementing 2nd LPF with damping ratio is to add resistor to inductor or capacitor of LC filter. In an industrial application, it is not practical to adopt damping resistor because it results in losses being proportional to square of current flowing through resistor. Instead of using damping resistors, the proposed active damping control(ADC) utilizes all pass filter(APF) and considers inherent processing delay of digital controller. The overall transfer function of the proposed method is the same as a 2nd LPF and its damping ratio is also controllable via control variables. Detailed design and implementation of controller is also presented. Experiments are conducted with a $7.5 \mathrm{kVA}$ induction motor drive system controlled by PWM converter and inverter. Test waveforms are also presented to verify the proposed LC filter control algorithm.
\end{abstract}

Keywords: Three-phase PWM inverter, Field oriented control, LC filter, Active damping control, All pass filter

\section{Introduction}

In recent years, fossil fuel used as main energy resource is primarily recognized as a major cause of environmental problems. As a result, alternative energy sources and technologies using renewable energy sources, i.e. wind turbine, photovoltaic energy, have been growing. Especially, wind energy has been recognized as one of the most promising renewable energy resources available. It is estimated that $12 \%$ of the world's electricity will be provided from wind energy by $2020[1,2]$.

In a renewable application such as wind turbine, lots of doubly fed induction generators(DFIGs) are used due to its low cost despite its disadvantage of having a wound rotor and slip-ring. It requires only $25 \%$ of rated, 4-quadrant $\mathrm{ac} / \mathrm{dc} / \mathrm{ac}$ PWM converters. AC grid side converter controls DC-link voltage and is connected to the grid. Generator side inverter controls the rotor speed and is connected to a wound rotor through slip-ring electrically. Mechanical friction of slip-ring lead to regular maintenance. But some applications such as off-shore wind generations adopt permanent magnet synchronous motor(PMSM) because of its high efficiency and maintenance. Maximum power point tracking(MPPT) is usually adopted to harvest as much energy as possible in a renewable energy application. As the maximum output power of a generator produced in a given wind speed is related to the rotor speed of DFIG, PWM inverter should control the rotor speed of DFIG to

$\dagger$ Corresponding Author: Dept. of Electrical Engineering, Hanyang University, Korea. (dshyun@hanyang.ac.kr)

* Dept. of Electrical Engineering, Hanyang University, Korea. (kskim @ hanyang.ac.kr)

Received: July 23, 2014; Accepted: February 16, 2015 extract the maximum power. The speed control of a generator/motor is based on a field oriented control in a synchronous reference frame [3-5].

PWM inverter has several problems in terms of not only differential mode harmonics but also common mode harmonics. The high $\mathrm{dv} / \mathrm{dt}$ output voltage causes reflections in the cable and causes a generator/motor terminal voltage to be increased up to double of voltage step. Spike voltage caused by a high $\mathrm{dv} / \mathrm{dt}$ has serious effect on a generator/ motor insulation and can lead to early failure of a generator / motor system. PWM inverter also generates high frequency common mode voltage which may increase the bearing current of equipments connected through its shaft. The bearing current generates noises and breaks the bearings in severe cases [6-8].

So, several papers suggested filter configurations attached to the output of PWM inverter to limit the spike of terminal voltage. $\mathrm{RC}$ filter matches the cable impedance so that the reflection and spike voltage is minimized. LCR filter consists of reactor, capacitor, and resistor. Resistor is inserted to damp the resonance of LC circuit. Resistor of RC and LRC filter generates losses and decreases the efficiency of overall system. LC filter has advantages that it generates nearly sinusoidal output voltage waveform and overall losses are considerably lower than RC and LCR filter. Several methods have been suggested that give a guide for the optimal design of LC filter and control method of PWM inverter with LC filter. As rules of thumb, the resonance frequency of LC filter should be ten times higher than fundamental frequency and lower than at least half of switching frequency. Filter size should be also as small as possible for economic reasons [4, 9-13]. 
Stability problem caused by resonance of LC filter has been very critical control issues. Several methods have been suggested, but they have severe drawbacks for industrial application. Active damping methods without resistor have been presented. Dead beat control method did not consider sample delay caused by micro processor [11]. Adding damping resistor in series with filter capacitor or in parallel with filter inductor is a well known method as a passive damping. Stability analysis and optimal design procedures are also well defined. But additional losses caused by damping resistors are inevitable. Lead-lag compensator requires a compromise between compensation and noise amplification $[12,13]$.

This paper suggests a new and robust LC filter control method which takes into consideration inherent processing delay of digital controller and describes design parameters in detail.

\section{Three-phase PWM Inverter with LC Filter}

\subsection{System configuration and control}

The representative configuration of a three-phase PWM inverter with LC filter is shown in Fig. 1. The inverter controls wind turbine which usually adopts DFIGs or PMSM as generator.

The meaning of variables and symbols are as follows.

$\mathrm{V}_{\mathrm{ix}} \quad$ : PWM inverter output phase voltage[V]

$\mathrm{L}_{\mathrm{f}} \quad:$ Filter inductance per phase[H]

$\mathrm{i}_{\mathrm{ix}} \quad$ : Filter inductor phase current[A]

$\mathrm{C}_{\mathrm{f}} \quad$ : Filter capacitance per phase[F]

$\mathrm{V}_{\mathrm{Cx}} \quad$ : Filter capacitor phase voltage[V]

$\mathrm{i}_{\mathrm{Cx}} \quad$ : Filter capacitor phase current[A]

$\mathrm{i}_{\mathrm{sx}} \quad:$ Generator/motor phase current[A]

suffix : Three phase $(x=u, v$, or $w)$

Wind turbine usually controls the speed of generator to extract maximum output power from wind speed. The field oriented control(FOC) in a synchronous reference frame is adopted. Synchronous reference frame can be aligned with stator flux, air-gap flux, or rotor flux. Here, flux control and torque control is based on d-axis current control and qaxis current control respectively. The block diagram of speed control and dq-axis current control in a synchronous

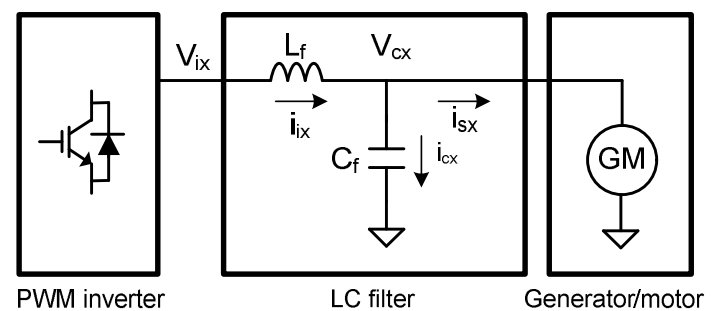

Fig. 1. Configuration of PWM inverter with LC filter

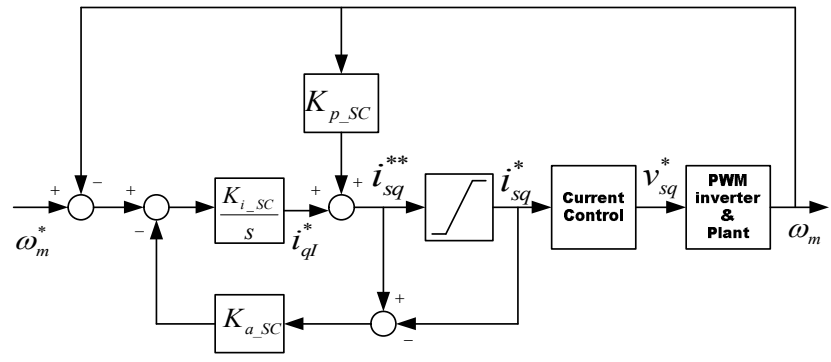

(a) Speed control

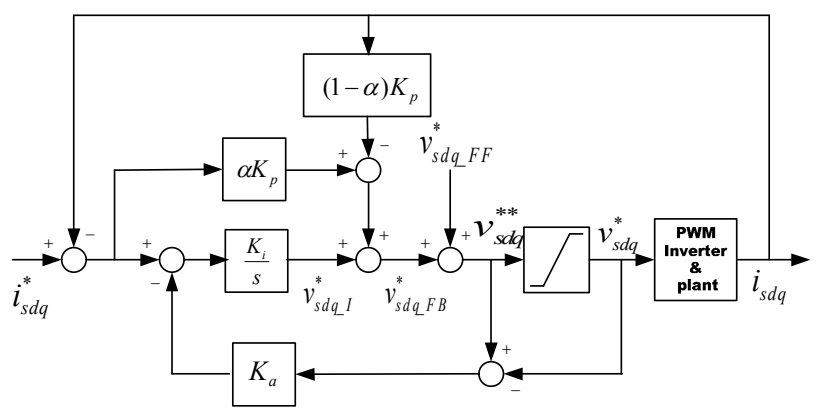

(b) Current control in a synchronous reference frame

Fig. 2. Control block diagram

reference frame is represented in Fig. 2(a) and (b) respectively. The feed forward term in a current control is used for decoupled current control.

Parameter estimation and dead time compensation technique for improving performance of field oriented control (FOC) have been suggested. Details on speed control, flux control, and torque control are found in literature [14-19].

\subsection{Analysis of PWM inverter with LC filter}

LC filter connected to an induction motor forms an equivalent LCL circuit as shown in Fig. 3(a). Filter capacitor voltage is the terminal voltage of an induction motor. Stator stray inductance(Ls) of an induction motor is

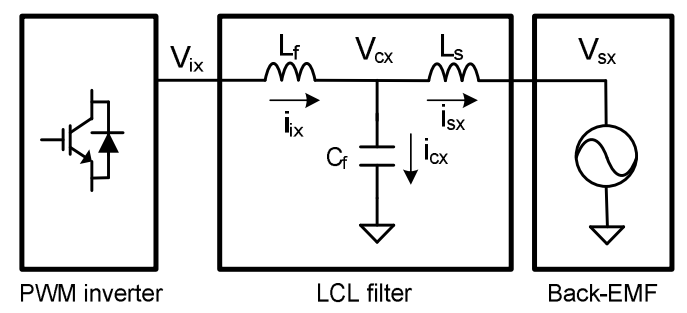

(a) Equivalent circuit

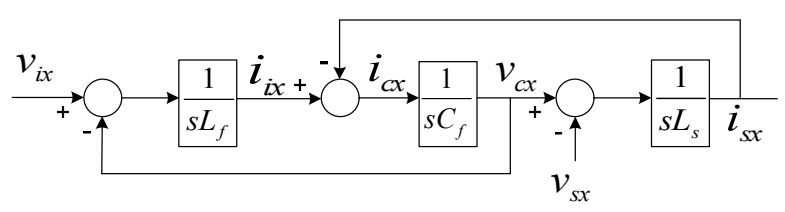

(b) Block diagram of equivalent circuit

Fig. 3. LC filter connected to a generator/motor 
connected to LC filter and back-EMF is considered as a voltage source(Vsx). Block diagram of an equivalent circuit of LCL filter is represented in Fig. 3(b). In practice, resistances of inductors and capacitors should be kept as small as possible in order to minimize their losses. Equivalent circuit of Fig. 3 omitted resistances for simple analysis.

Eq. (1) can be written for each phase of the inverter system in Fig. 3.

$$
\begin{array}{ll}
v_{i x}=L_{f} \cdot i_{i x}^{\prime}+v_{c x}, & v_{c x}=L_{s} \cdot i_{s x}^{\prime}+v_{s x} \\
i_{c x}=C_{f} \cdot v_{c x}^{\prime}, & i_{i x}=i_{c x}+i_{s x}
\end{array}
$$

where $v_{i x}=\left[\begin{array}{lll}v_{i a} & v_{i b} & v_{i c}\end{array}\right], x^{\prime}$ is derivative of variable $\mathrm{x}$.

Eq. (1) in a natural reference frame can be transformed as Eq. (2) in a synchronous reference frame where complex vector notations are used.

$$
v_{i d q}=\frac{L_{f}}{L_{e q}}\left(\frac{v_{c d q}^{\prime \prime}}{\omega_{L C L}^{2}}+v_{c d q}\right)-\frac{\omega^{2}}{\omega_{n}^{2}} \cdot v_{c d q}+j \frac{2 \omega}{\omega_{n}^{2}} \cdot v_{c d q}^{\prime}-\frac{L_{f}}{L_{s}} \cdot v_{s d q}
$$

where $\omega_{n}=\frac{1}{\sqrt{L_{f} \cdot C_{f}}}$ is the angular resonance frequency of LC filter[rad/s], $L_{e q}=\frac{L_{f} \cdot L_{s}}{L_{f}+L_{s}}$ is the equivalent inductance of $\mathrm{L}_{\mathrm{f}}$ and $\mathrm{L}_{\mathrm{s}}[\mathrm{H}], \quad \omega_{L C L}=\frac{1}{\sqrt{L_{e q} \cdot C_{f}}}$ is the angular resonance frequency of LCL circuit[rad/s], and $v_{i d q}=v_{i d}+j v_{i q}$ is a complex vector notation.

The transfer function of an equivalent LCL filter is represented as Eq. (3).

$$
G_{L C L}(s)=\frac{v_{c d q}(s)}{v_{i d q}(s)}=\frac{v_{s d q}(s)}{v_{i d q}(s)}=\frac{L_{e q}}{L_{f}} \cdot \frac{\omega_{L C L}^{2}}{s^{2}+\omega_{L C L}^{2}}
$$

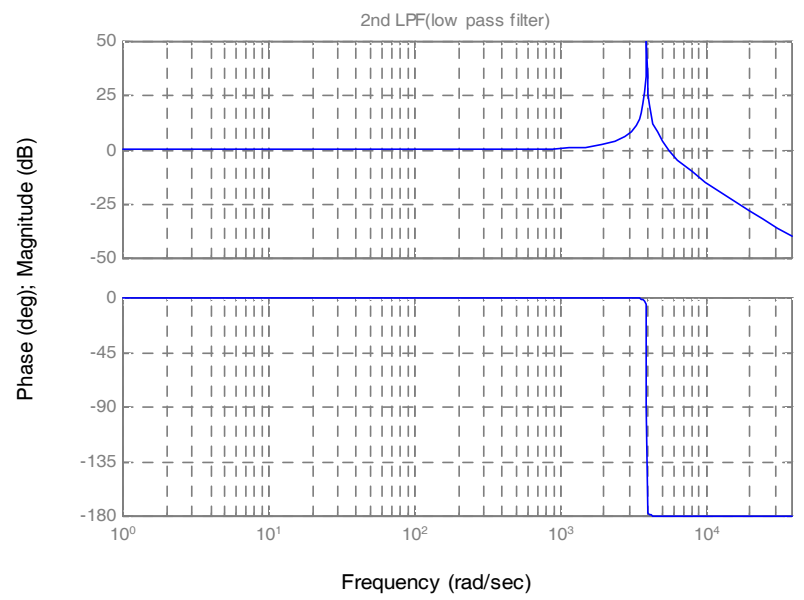

Fig. 4. Bode plot of LC filter
Bode plot of Eq. (3) is shown in Fig. 4 which has infinite or very high gain at the resonance frequency. It can lead to sustaining oscillation of system if proper steps for damping the resonance are not taken.

Active damping control is just adding non zero damping ratio to Eq. (3) so that Eq. (3) is reshaped into a typical 2nd LPF of Eq. (4). Damping ration( $\zeta$ ) is control gain which can be configured by software.

$$
G_{L P F}(s)=\frac{v_{c d q}(s)}{v_{i d q}^{*}(s)}=\frac{\omega_{L C L}^{2}}{s^{2}+2 \zeta \omega_{L C L} \cdot s+\omega_{L C L}^{2}}
$$

It can be done by feedback of capacitor voltage derivatives multiplied by proper gain. Fig. 5 is the block diagram of active damping control of LCL filter.

Fig. (6) is the bode plot of Eq. (4) which adopts active damping control. Comparing it with Fig. (4), it shows damped characteristics.

Now, all that is needed to implement active damping control is to synthesize the derivative of capacitor voltages. Derivative of capacitor voltages can be calculated from capacitor currents as Eq. (5).

$$
\begin{aligned}
& i_{c x}=C_{f} \cdot v_{c x}^{\prime} \\
& i_{c d q}=s C_{f} \cdot v_{c d q}
\end{aligned}
$$

Measuring capacitor currents requires additional $\mathrm{H} / \mathrm{W}$, i.e. current sensors. Additionally, filter capacitor currents in a PWM inverter contain high frequency switching components so that precise and complicate signal processing are needed for accurate measurement.

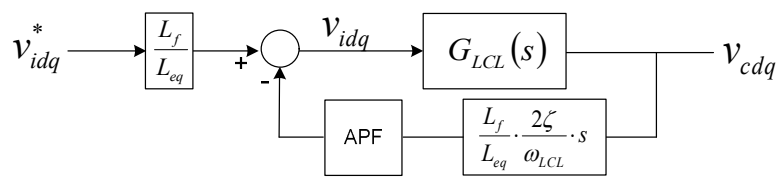

Fig. 5. Damping control of LCL filter

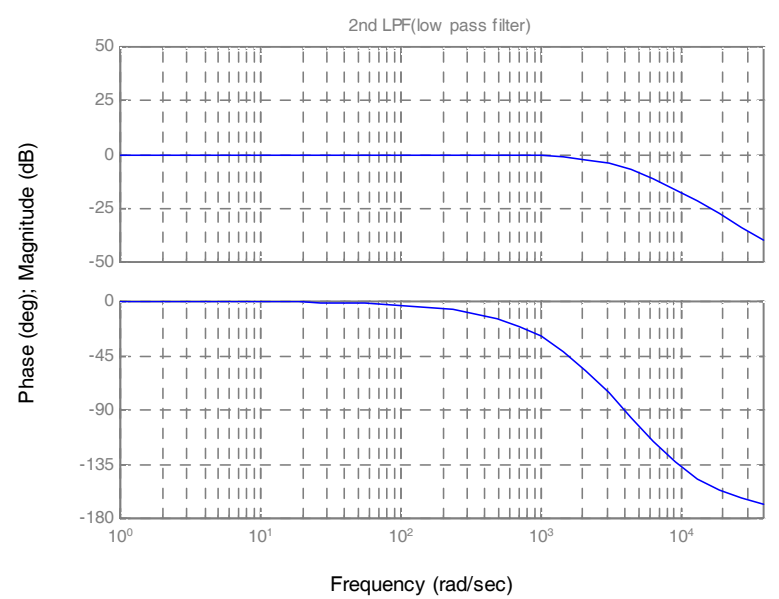

Fig. 6. Bode plot of Eq. (4) 
Another approach is to calculate the derivative of capacitor voltage. Mathematical expression of the derivative is simple to implement in a digital control using Eq. (6). But digital derivative technique is also very sensitive to measurement noise of capacitor voltage so that it is not practical to use in an industrial application.

$$
v^{\prime}[n]=\frac{v[n]-v[n-1]}{T_{s}}
$$

\section{Control strategy}

\subsection{Analysis of proposed active damping}

The proposed control method uses all pass filter(APF) and take into account inherent processing delay of digital control. The first step for active damping control is to extract the resonance frequency components from filter capacitor voltages. Resonance component can be extracted by subtracting low pass filtered signal from measured dq-axis voltages in a synchronous reference frame. The resonance frequency component extracted from filter capacitor voltages can be represented as Eq. (7).

$$
v_{h}=v_{m h} \cdot \sin \left(\omega_{L C L} \cdot t+\varphi_{h}\right)
$$

where $v_{m h}$ and $\varphi_{h}$ are magnitude and phase delay of resonance component.

Derivative of Eq. (7) is exactly 90 degrees delayed signal multiplied by resonance angular frequency as represented in Eq. (8).

$$
\begin{aligned}
s v_{h}=s v_{c d q} & =\omega_{L C L} \cdot v_{m h} \cdot \cos \left(\omega_{L C L} \cdot t+\varphi_{h}\right) \\
& =-\omega_{L C L} \cdot v_{m h} \cdot \sin \left(\omega_{L C L} \cdot t+\varphi_{h}-\frac{\pi}{2}\right)
\end{aligned}
$$

Now, the proposed method uses APF to generate the derivative of capacitor voltage which is exactly 90 degrees delayed signal. Transfer function of APF is written as Eq. (9). Pole and zero of $\operatorname{APF}\left(\omega_{A}\right)$ is shown in Fig. 7 (a) and its bode plot for frequency characteristics is shown in Fig. 7 (b). The magnitude is unit constant and phase delay is dependent on frequency.

$$
G_{A}(s)=-\frac{s-\omega_{A}}{s+\omega_{A}}
$$

For example, if cut off frequency of APF is same as resonance frequency of LCL filter $\left(\omega_{A}=\omega_{L C L}\right)$, the output of APF is exactly 90 degrees delayed signal as Eq. (10).

$$
A P F\left(v_{h}\right)=v_{m h} \cdot \sin \left(\omega_{L C L} \cdot t+\varphi_{h}-\frac{\pi}{2}\right)
$$

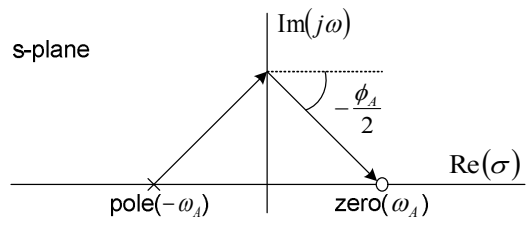

(a) Pole and zero of APF in s-plane

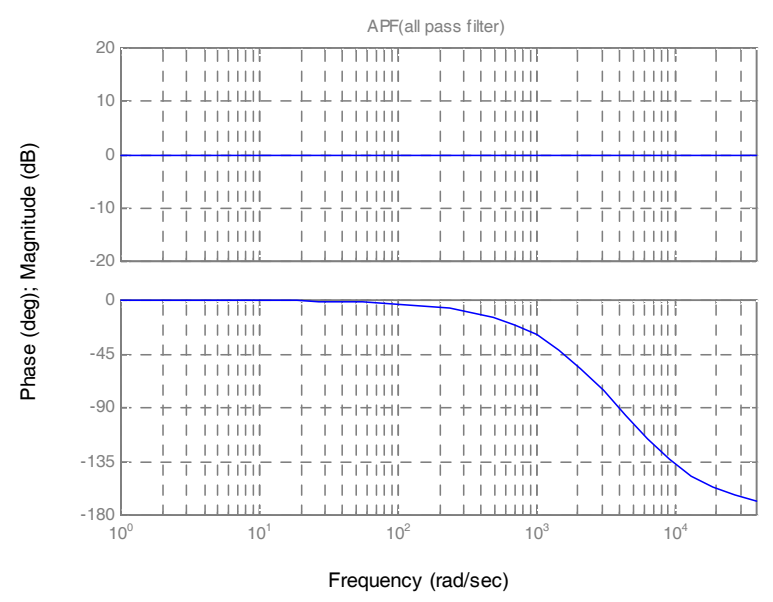

(b) Bode plot of APF

Fig. 7. Characteristics of APF

\subsection{Implementation of proposed active damping}

Digital control using micro process has its inherent processing delay which consists of computational delay and PWM delay. As double sampling technique is adopted, processing delay $\left(\mathrm{T}_{\text {delay }}\right)$ is one and half sample because computational delay and PWM delay are one sample $\left(\mathrm{T}_{\mathrm{s}}\right)$ and half sample $\left(0.5 \mathrm{~T}_{\mathrm{s}}\right)$ respectively. The delay angle of APF in Eq. (10) is adjusted so that total delay of APF and processing delay is 90 degrees. Eq. (11) is the APF delay angle $\left(\varphi_{A}\right)$ considering processing delay.

$$
\varphi_{A}=\frac{\pi}{2}-T_{\text {delay }} \cdot \omega_{L C L}=\frac{\pi}{2}-1.5 T_{s} \cdot \omega_{L C L}
$$

As long as phase delay is determined according to Eq. (11), pole and zero of APF can be calculated by Eq. (12).

$$
\omega_{A}=\frac{\omega_{L C L}}{\tan \varphi_{A}}
$$

Digital approximation of APF can be done with different methods, i.e. backward approximation, forward approximation, and bilinear approximation. Forward and backward method may lead to unstable and bad phase delay. Bilinear approximation transforms imaginary axis of continuous system in s-plane into unit circuit of discrete system in zplane so that it performs stable and good phase response. Among above, bilinear approximation using Eq. (13) is adopted. 


$$
s=\frac{2}{T_{s}} \frac{z-1}{z+1}
$$

Digital equivalent of Eq. (9) can be represented as Eq. (14) by using bilinear approximation.

$$
G_{A}(z)=-\frac{\left(\frac{2}{T_{s}}-\omega_{A}\right) z-\left(\frac{2}{T_{s}}+\omega_{A}\right)}{\left(\frac{2}{T_{s}}+\omega_{A}\right) z-\left(\frac{2}{T_{s}}-\omega_{A}\right)}
$$

\section{Experiment}

Experimental system is set up as shown in Fig. 8 and Table 1 shows parameters of experiment system.

It is composed of boost type PWM converter, PWM inverter and human machine interface (HMI). HMI communicates with controllers through RS-232 to control experimental system, e.g. setting up system parameters,

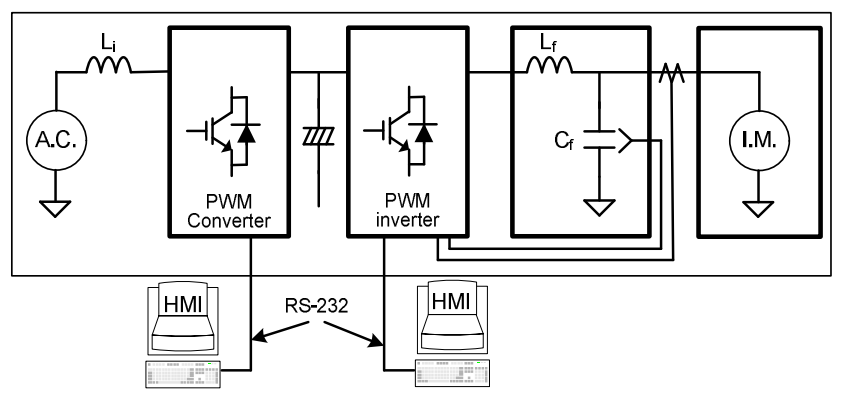

Fig. 8. Configuration of experimental system

\begin{tabular}{|c|c|}
\hline & Description \\
\hline $\begin{array}{c}\text { PWM } \\
\text { converter }\end{array}$ & $\begin{array}{l}\text { I. Boost Type PWM converter } \\
\text { II. Ratings } \\
\text { Capacity }=7.5[\mathrm{kVA}] \\
\mathrm{V}_{\mathrm{LL}}=380[\mathrm{~V}], \mathrm{I}=11[\mathrm{~A}] \\
\mathrm{V}_{\mathrm{dc} \text { ref }}=650[\mathrm{Vdc}], \mathrm{Li}=1.5[\mathrm{mH}] \\
\text { III. Controller } \\
\text { Ts }=250[\mathrm{usec}], \mathrm{f}_{\mathrm{sw}}=2[\mathrm{kHz}]\end{array}$ \\
\hline $\begin{array}{l}\text { PWM } \\
\text { inverter }\end{array}$ & $\begin{array}{ll}\text { I. } & \text { Ratings } \\
& \text { Capacity }=7.5[\mathrm{kVA}], \\
& \mathrm{V}_{\mathrm{LL}}=440[\mathrm{~V}], \mathrm{I}=10[\mathrm{~A}], \\
\text { II. } & \text { Controller } \\
& \mathrm{T}_{\mathrm{s}}=250[\mathrm{usec}], \mathrm{f}_{\mathrm{sw}}=2[\mathrm{kHz}]\end{array}$ \\
\hline LC-filter & $\begin{array}{ll}\text { I. } & \text { Parameters } \\
& \mathrm{L}_{\mathrm{f}}=1.6[\mathrm{mH}], \mathrm{C}_{\mathrm{f}}=50[\mathrm{uF}] \\
\text { II. } & \text { Connection Type } \\
& \text { Y-connected }\end{array}$ \\
\hline \multirow[t]{2}{*}{ I.M. } & $\begin{array}{ll}\text { I. } & \text { Ratings } \\
& \mathrm{Po}=5.5[\mathrm{~kW}], \mathrm{V}_{\mathrm{LL}}=460[\mathrm{~V}], \mathrm{I}=11[\mathrm{~A}], \\
\text { freq }=60[\mathrm{~Hz}], \mathrm{P}=4[\text { pole }], \\
\text { Speed }=1780[\mathrm{rpm}], \mathrm{Jm}=0.076\left[\mathrm{kgm}^{2}\right] \\
\text { II. } \text { Motor parameters } \\
\mathrm{Rs}=0.582[\mathrm{ohm}], \mathrm{Rr}=0.327[\mathrm{ohm}], \\
\mathrm{Ls}=\mathrm{Lr}=0.11383[\mathrm{H}], \mathrm{Lm}=0.10628[\mathrm{H}]\end{array}$ \\
\hline & Description \\
\hline
\end{tabular}

Table 1. Parameters of experimental system
Table 2. Parameters of controller

\begin{tabular}{c|c|c}
\hline & Description & Value \\
\hline \multirow{4}{*}{ LCL filter } & $\mathrm{L}_{\mathrm{f}}$ & $1.6[\mathrm{mH}]$ \\
\cline { 2 - 3 } & $\mathrm{L}_{\mathrm{S}}$ & $7.55[\mathrm{mH}]$ \\
\cline { 2 - 3 } & $\mathrm{C}_{\mathrm{f}}$ & $50[\mathrm{uF}]$ \\
\cline { 2 - 3 } & $\mathrm{L}_{\mathrm{eq}}$ & $1.32[\mathrm{mH}]$ \\
\cline { 2 - 3 } $\mathrm{APF}$ & $\omega_{L C L}$ & $3,892[\mathrm{rad} / \mathrm{s}]$ \\
\hline \multirow{4}{*}{} & $T_{s}$ & $250[\mathrm{usec}]$ \\
\cline { 2 - 3 } & $\phi_{A}$ & $0.11[\mathrm{rad}]$ \\
\cline { 2 - 3 } & $\omega_{A}$ & $34,847[\mathrm{rad} / \mathrm{s}]$ \\
\hline Damping ratio & $\zeta$ & 1 \\
\hline
\end{tabular}

monitoring system status. PWM converter is connected to the grid and operates in unit power factor to supply DC voltage for inverter. PWM inverter using field oriented control drives an induction motor. LC filter is installed at the output of PWM inverter so that it filters out switching frequency and supplies sinusoidal output voltage to an induction motor. The resonance frequency of LCL filter is $619[\mathrm{~Hz}]$ which is far away from $60[\mathrm{~Hz}]$ power frequency.

Insulated gate bipolar transistor (IGBT) is used as main switching device. PWM inverter switching frequency is 2 $[\mathrm{kHz}]$ and double sample method is adopted. Digital controllers are implemented with micro control unit (MCU) from Texas Instrument (TI). MCU has 16 channels of analog-digital converter (ADC), high resolution PWM Logic with dead time generation, and communication peripherals.

\subsection{Experimental results}

Experiments are conducted to verify the proposed active damping control and an induction motor control.

Fig. 9 is test waveforms of LC filter in case the proposed active damping control is adopted. $\mathrm{C} 1$ and $\mathrm{C} 2$ in Fig. 9 are $\mathrm{q}$-axis voltage reference and filter capacitor voltage in a synchronous reference frame. $\mathrm{C} 4$ is u-phase voltage waveform measured by digital oscilloscope. Active damping control is not activated in case of Fig. 9 (a). Large overshoot and oscillation appear in filter capacitor voltage. Filter control is turned on in case of Fig. 9 (b). Damping ratio is set to unit so that it is the same as the characteristic of a $2^{\text {nd }}$ LPF without overshoot of filter output voltage. Test results shows that resonance of LC filter is suppressed effectively by the proposed active damping control.

Tests for verifying the robustness in terms of parameter errors are carried out. Both inductance and capacitance of controller parameters are changed to $80 \%$ and $120 \%$ of the real value. Fig. 10 (a) is the test waveform where the value of inductance and capacitance of controller is set to 1.28 $[\mathrm{mH}]$ and $40[\mathrm{uF}]$ respectively. It shows under damped $2^{\text {nd }}$ LPF response with slight overshoot of filter capacitor voltage. Fig. 10 (b) is the test waveform where the value of inductance is set by $1.92[\mathrm{mH}]$ and the value of capacitance is adjusted by $60[\mathrm{uF}]$. Response to step input is over 


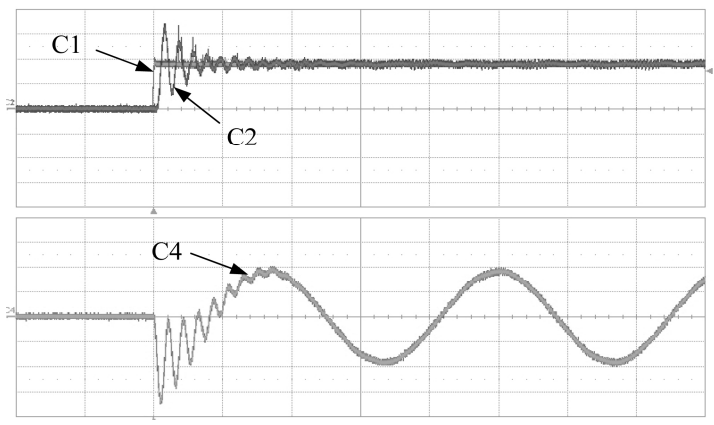

(a) without filter control

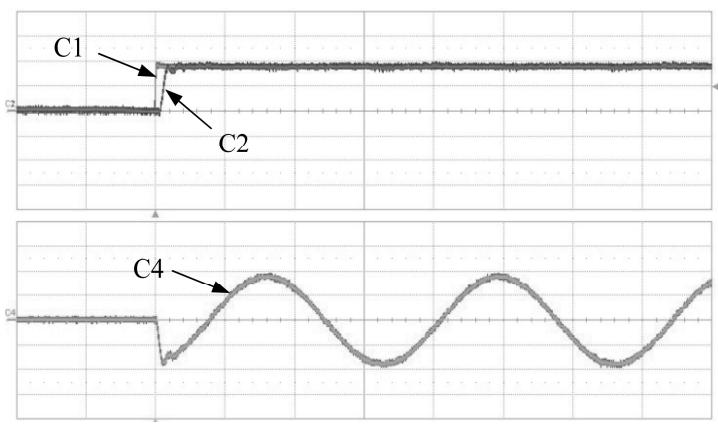

(b) with filter control

Fig. 9. Experimental waveforms of LC filter, $\mathrm{C} 1$ : q-axis voltage reference $(100[\mathrm{~V} / \mathrm{div}]), \mathrm{C} 2$ : q-axis voltage feedback(100[V/div]), C4 : u-phase voltage (100 [V/div]), time : $10[\mathrm{~ms} / \mathrm{div}]$

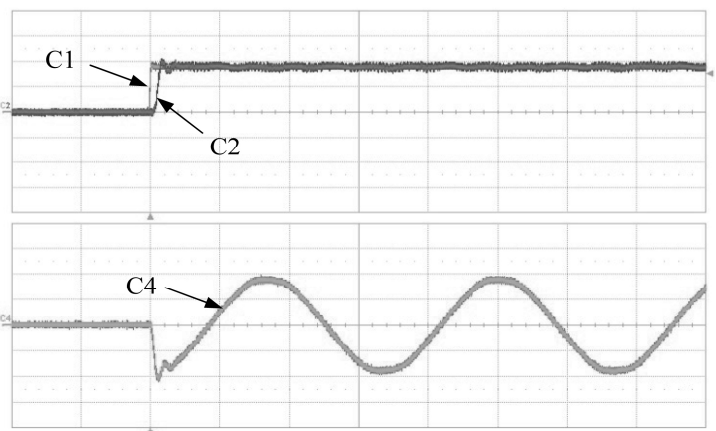

(a)

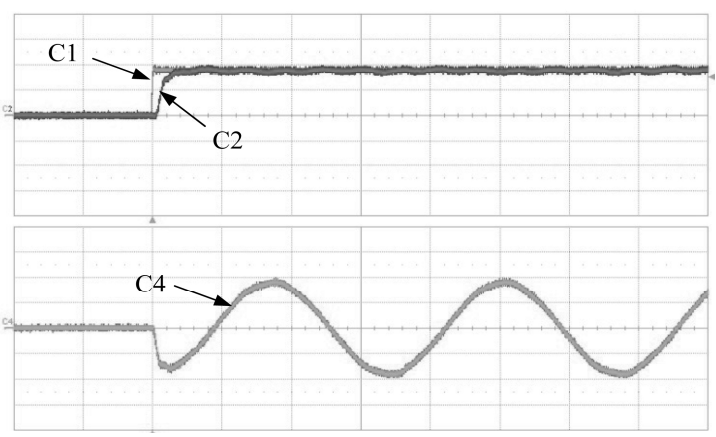

(b)

Fig. 10. Experimental waveforms of parameter errors, (a) parameter value $=80 \%$, (b) parameter value $=120 \%$, $\mathrm{C} 1$ : q-axis voltage reference(100[V/div]), C2 : qaxis voltage feedback(100[V/div]), C4 : u-phase voltage $(100[\mathrm{~V} / \mathrm{div}])$, time : $10[\mathrm{~ms} / \mathrm{div}]$ damped waveform with slow response of filter capacitor voltage. Performance of the proposed active damping control with $20 \%$ parameter error are affected slightly because it cannot calculate derivative of capacitor voltage as Eq. (11), e.g. exactly 90 degrees delayed signal, due to incorrect resonance frequency information $\left(\omega_{L C L}\right)$. But Test results show that there is no sustained oscillation of filter capacitor voltage.

Fig. 11 is current control response to a step reference where the proposed active damping control is used. $\mathrm{C} 1$ and $\mathrm{C} 2$ are $\mathrm{q}$-axis current reference and feedback in a synchronous reference frame. C3 and C4 are u-phase current and u-phase voltage measured by oscilloscope. It shows a good performance both in a transient state and in a steady state.

Speed control based on FOC is tested as shown in Fig. 12. $\mathrm{C} 1$ and $\mathrm{C} 2$ are speed reference and feedback. Speed reference varies from $-1500[\mathrm{rpm}]$ to 1500 [rpm] with ramp. C3 and $\mathrm{C} 4$ are u-phase current and u-phase voltage measured by oscilloscope. The speed of induction motor follows exactly as the reference. Phase voltages and currents of an induction motor are also sinusoidal as expected.

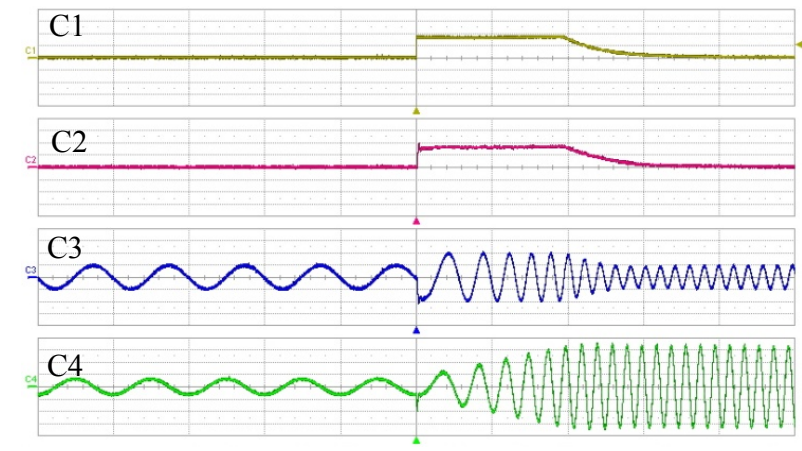

Fig. 11. Experimental waveforms of current control, $\mathrm{C} 1$ : q-axis current reference(10 [A/div]), C2: q-axis current feedback(10 [A/div]), C3 : u-phase current (10 [A/div]), C4 : u-phase voltage(100 [V/div]), time : $100[\mathrm{~ms} / \mathrm{div}]$

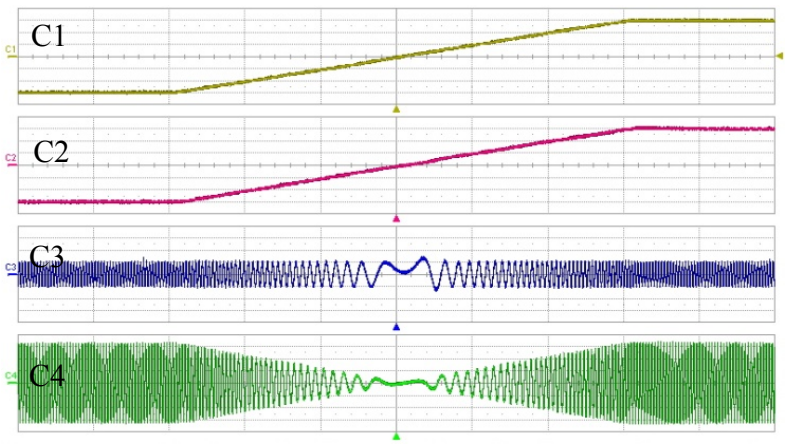

Fig. 12. Experimental waveforms of speed control, C1: speed reference (500 [rpm/div]), C2: speed feedback (500 [rpm/div]), C3: u-phase current (10 [A/div]), C4: u-phase voltage (100 [V/div]), time: 500 $[\mathrm{ms} / \mathrm{div}]$ 


\section{Conclusion}

A new control strategy of PWM inverter with output LC filter is proposed. It needs only software implementation and control variable such as damping ratio is easily controlled by software. It does not apply any noise sensitive technique for implementation so that it can be used in an industrial application. It is also verified by experiments to be robust against inaccuracy of filter parameters.

$7.5[\mathrm{kVA}] \mathrm{AC} / \mathrm{DC} / \mathrm{AC}$ system was set up to verify the proposed method. A field oriented control is adopted for motor drive. Flux and speed control is based on d-axis and q-axis PI-type current control in a synchronous reference frame respectively. Control algorithms are implemented in a digital controller using high performance DSP. Waveforms show that FOC of an induction motor with the proposed filter control works well without sustained oscillation of LC filter. Experimental results verify the effectiveness of the proposed algorithm.

\section{References}

[1] Raymundo E. Torres-Olguin, Marta Molinas, and Tore Undeland, "Offshore Wind Farm Grid Integration by VSC Technology with LCC-Based HVDC Transmission", IEEE Transactions on Sustainalbe Energy, Vol. 3, No. 4, pp. 899 907, October 2012.

[2] Risheng Li, Serhiy Bozhko, and Greg Asher, "Frequency Control Design for Offshore Wind Farm Grid With LCC-HVDS Link Connection", IEEE Transactions on Power Delivery, Vol. 23, No. 3, pp. 1085 1092, May 2008.

[3] Dawei Xiang, Li Ran, Jim R. Bumby, Peter J. Tavner, and Shunchang Yang, "Coordinated Control of an HVDC Link and doubly fed induction generator in a large offshore wind farm", IEEE Transactions on Power Delivery, Vol. 21, No. 21, pp. 463 471, January 2006.

[4] Hae-Gwang Jeong, Dong-Keun Yoon, and Kyo-Beum Leei, "Design of an LCL-Filter for Three-Parallel Operation of Power Converters in Wind Turbines", Journal of Power Electronics, Vol. 13, No. 3, May 2013.

[5] Ali Bechouche, Djaffar Ould Abdeslam, Tahar Otmane-Cherif, and Hamid Seddiki, "Adaptive Neural PLL for Grid-connected DFIG Synchronization", Journal of Power Electronics, Vol. 14, No. 3, pp. 608620, May 2014.

[6] Satoshi Ogasawara, and Hirofumi Akagi, "Modeling and Damping of High-Frequency Leakage Currents in PWM Inverter-Fed AC Motor Drive Systems", IEEE Transactions on Industry Applications, Vol. 32, No. 5, pp. 1105 1114, September/October 1996.

[7] Annette von Jouanne, Dudi A. Rendusara, Prasad N. Enjeti, and James Will Gray, "Filtering Techniques to Minimize the Effect of Long Motor Leads on PWM Inverter-Fed AC Motor Drive Systems", IEEE Transactions on Industry Applications, Vol. 32, No. 4, pp. 919 925, July/August 1996.

[8] Jay M. Erdman, Russel J. Kerkman, David W. Schlegel, and Gary L. Skibinski, "Effect of PWM Inverters on AC Motor Bearing Currents and Shaft voltages", IEEE Transactions on Industry Applications, Vol. 32, No. 2, pp. 250 259, March/April 1996.

[9] Mari Kojima, Kazufumi Hirabayashi, Yoshitaka Kawabata, Emenike C. Ejiogu, and Takao Kawabata, "Novel Vector Control System Using DeadbeatControlled PWM Inverter With Output LC Filter", IEEE Transactions on Industry Applications, Vol. 40, No. 1, pp. $162 \sim 169$, January/February 2004.

[10] Juergen K. Steinke, "Use of an LC Filter to Achieve a Motor-friendly Performance of the PWM Voltage Source Inverter", IEEE Transactions on Energy Conversion, Vol. 14, No. 3, pp. 649 655, September 1999.

[11] Osman Kukrer, "Deadbeat Control of a Three-Phase Inverter with an Output LC Filter", IEEE Transactions on Power Electronics, Vol. 11, No. 1, pp. 16 23, January 1996.

[12] M. Liserre, F. Blaabjerg, and A. Dell'Aquila, "Stepby-step design procedure for a grid-connected threephase PWM Voltage Source Converter," Int. J. Electron., vol. 91, no. 8, pp. 445-460, Aug. 2004.

[13] Marco Liserre, Frede Blaabjerg, and Steffan Hansen, "Design and Control of an LCL-Filter-Based ThreePhase Active Rectifier", IEEE Transactions on Industry Applications, Vol. 41, No. 5, pp. 1281 1291, September/October 2005.

[14] Constantine Mastorocostas, Iordanis Kioskeridis, and Nikos Margaris, "Thermal and Slip Effects on Rotor Time Constant in Vector Controlled Induction Motor Drives," IEEE Transactions on Power Electronics, Vol. 21, No. 2, pp. 495 504, March 2006.

[15] Jinhwan Jung, and Kwanghee Nam, "A Dynamic Decoupling Control Scheme for High-Speed Operation of Induction Motors", IEEE Transactions on Industrial Electronics, Vol. 46, No. 1, pp. 100 110, February 1999.

[16] J. W. Choi and S. K. Sul, "A new compensation strategy reducing voltage/current distortion in PWM VSI systems operating with low output voltages," IEEE Transactions on Industry Applications, vol. 31, pp. 1001 1008, Sept./Oct. 1995.

[17] Jong-Woo Choi, and Seung-Ki Sul, "Inverter Output Voltage Synthesis Using Novel Dead Time Compensation", IEEE Transactions on Power Electronics, Vol. 11, No. 2, pp. 221 227, March 1996.

[18] Jul-Ki Seok, Seung-I11 Moon, and Seung-Ki Sul, "Induction Machine Parameter Identification using PWM Inverter at Standstill”, IEEE Transactions on 
Energy Conversion, Vol. 12, No. 2, pp. 127 132, June 1997.

[19] Ouk-Sang Park, Je-Wook Park, Chae-Bong Bae, and Jang-Mok Kim "Compensation Strategy to Eliminate the Effect of Current Measurement Offsets in GridConnected Inverters", Journal of Power Electronics, Vol. 14, No. 2, pp. 383-391, March 2014.

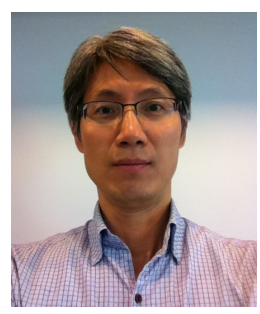

Kwang-Seob Kim He received B.S and M.S degree in electrical engineering from Hanyang University in 1994 and 1996 respectively. His research interests are high power converter, $\mathrm{AC}$ drive system, robust control, and distributed energy resource.

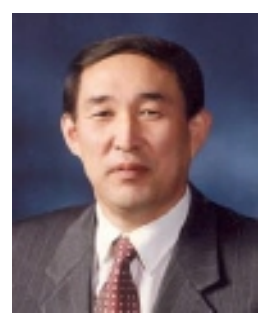

Dong-Seok Hyun He received the B.S. and M.S. degrees from Hanyang University, Seoul, Korea, in 1973 and 1978, respectively, and the Ph.D. degree from Seoul National University, Seoul, Korea, in 1986, all in electrical engineering. From 1976 to 1979 , he was a Researcher with the Agency of Defense Development, Korea. From 1984 to 1985, he was a Research Associate in the Department of Electrical Engineering, University of Toledo, Toledo, $\mathrm{OH}$, and from 1988 to 1989, he was a Visiting Professor in the Department of Electrical Engineering, Technical University of Munich, Germany. Since 1979, he has been with Hanyang University, where he is currently a Professor in the Department of Electrical Engineering. He is the author of more than 650 publications concerning electric machine design, highpower engineering, power electronics, and motor drives. His research interests include power electronics, motor drives, traction, and their control systems. Dr. Hyun is a member of the IEEE Power Electronics, Industrial Electronics, Industry Applications, and Electron Devices Societies. He is also a member of the Institution of Engineering and Technology, the Korean Institute of Power Electronics, and the Korean Institute of Electrical Engineers. 